\title{
DIELECTRIC PROPERTIES OF DEEP ICE CORES WITH AIR-HYDRATE INCLUSIONS \\ (Abstract)
}

\author{
by \\ Shinji Mae, Takeo Hondoh and Masayoshi Nakawo \\ (Department of Applied Physics, Faculty of Engineering, Hokkaido University, Sapporo 060, Japan) \\ and \\ C.C. Langway, Jr \\ (Department of Geological Sciences, State University of New York at Buffalo, \\ 4240 Ridge Lea Road, Amherst, NY 14226, U.S.A.)
}

\begin{abstract}
Air-hydrate inclusions have been found in deep ice cores from Dye 3, Greenland, which were taken in August 1981. Although the concentration of the air-hydrate crystals decreased with time, when the core was stored at a temperature of $-50^{\circ} \mathrm{C}$, they still existed to an appreciable extent in 1985.

An ice specimen was cut out from the Dye 3 core at a depth of $1500 \mathrm{~m}$, where the volume fraction of the hydrate crystals was about $10^{-3}$ by volume. Its dielectric
\end{abstract}

properties were measured in September 1985, in a frequency range of $30-20 \times 10^{3} \mathrm{~Hz}$ and temperature range of $-20^{\circ}$ to $-90^{\circ} \mathrm{C}$. The activation energy obtained for the relaxation time of the Debye dispersion was about $0.2 \mathrm{eV}$, which is much smaller than that of pure ice.

The measurement was repeated once a month for about a year, and the sample was stored at a temperature of $-10^{\circ} \mathrm{C}$ between measurements. The time variation of the dielectric properties has been discussed in relation to the deterioration of the air-hydrate crystals. 